\title{
Validity of clinical diagnosis in dementia: a prospective clinicopathological study
}

\author{
PEKKA K MÖLSÄ, LEO PALJÄRVI, * JUHA O RINNE, URPO K RINNE, ERKKI SÄKÖ
}

From the Departments of Neurology and Pathology, ${ }^{*}$ University of Turku, Turku, Finland

SUMMARY With neuropathological diagnosis as the point of reference, the accuracy of clinical diagnosis was studied in a series of 58 demented patients. Alzheimer's disease and multi-infarct dementia were recognised with sensitivities and specificities exceeding $70 \%$, whereas combined dementia as a separate group was relatively unreliably diagnosed. The value of Hachinski's Ischaemic Score in differentiating between Alzheimer's disease and vascular dementias was demonstrated. Its performance was to some extent improved by assigning new weights to the items. In a logistic regression model, fluctuating course, nocturnal confusion, and focal neurological symptoms emerged as features with the best discriminating value, and helped to diagnose correctly $89 \%$ of the Alzheimer and $71 \%$ of the vascular dementia patients.

The major form of dementia in old age is senile dementia of Alzheimer type (SDAT), the most common type of Alzheimer's disease (AD). The neuropathological picture is characterised by three microscopical changes: neurofibrillary tangles and neuritic plaques in the neo- and paleocortex, together with granulovacuolar degeneration in the hippocampus. ${ }^{1}$ Multi-infarct dementia, the second most common cause of dementia, is due to multiple gross or microscopic infarcts, often widely spread throughout the brain tissue. ${ }^{2}$ In addition, many demented old people show a combination of changes, all of which may contribute to the dementing process. The most important combination is that of $\mathrm{AD}$ and ischaemic infarcts, or combined dementia.' A solid diagnostic differentiation of these conditions can only be made by a postmortem neuropathological examination. Brain biopsy can be used to identify the Alzheimer process during life, but this invasive procedure is not acceptable as a routine diagnostic method in senescence. Thus, the clinical identification of the major forms of senile dementia must be largely based on a careful analysis of clinical data. ${ }^{3}$

It is therefore of interest to investigate the accuracy of clinical diagnosis using neuropathological diagnosis as the point of reference..$^{4-6}$ An extensive

Address for reprint requests: Professor Urpo K Rinne, Department of Neurology, University of Turku 20520 Turku 52, Finland.

Received 19 October 1984 and in revised form 1 March 1985. Accepted 8 March 1985. retrospective study by Todorov et $\mathrm{al}^{4}$ comprised 776 patients studied during a period of ten years. In that study, the sensitivity of the clinical diagnosis was $28 \%$ for SDAT, $57 \%$ for multi-infarct dementia, and $30 \%$ for combined cases; the corresponding specificities were $43 \%, 39 \%$, and $48 \%$. Thus, the accuracy of clinical diagnosis proved poor. It would seem likely that better accuracy might be reached in a prospective study with uniform diagnostic criteria throughout the study period. We now report results of a prospective analysis of 58 demented patients. The systematic approach devised by Hachinski etal. ${ }^{7}$ was evaluated as a method to differentiate between AD and vascular dementia.

\section{Patients and methods}

\section{PATIENTS}

The 58 subjects in the present study came from the material of 421 patients identified in our community survey of dementia. $^{89}$ The diagnostic clinical information was collected in 1976-81, and the patients included in the present study constitute a consecutive series dying in the Turku City Hospital and coming to necropsy in 1979-82. There were 15 men and 43 women. Their ages at death varied from 59 to 95 years. Only three were under 65 ; the mean age was 79.2 years and SD 6.7 years.

Clinical diagnosis. Dementia was diagnosed, if there was a primarily occurring progressive deterioration of memory and other cognitive functions. The initial clinical evaluation included a thorough clinical examination supplemented with a short neuropsychological test battery including the tests of Isaacs and Walkey ${ }^{10-12}$ (questionnaire, paired-association test, building block test) as well as 
the cube test and number series of WAIS, and the test of comprehension by Luria ${ }^{13}$ (further details are given elsewhere $^{89}$ ). At the time, CT scan was not available for these patients.

If there was no evidence of a metabolic, toxic, traumatic, vascular or other symptomatic cause for dementia, a diagnosis of degenerative dementia, or AD, was made. The diagnosis of vascular dementia was based on the evaluation of items constituting Hachinski's Ischaemic Score (table 3). Hachinski et al found that patients with degenerative dementia had scores ranging from 0 to 4 , whereas multiinfarct dementia patients scored 7 or higher. Using another vascular scale, Portera-Sanchez et al $^{14}$ suggested that combined cases (having AD and vascular lesions simultaneously) could be recognised on the basis of having intermediate vascular scores. We applied this principle on the Hachinski Score as follows: a score of $0-4$ is consistent with the diagnosis of $\mathrm{AD}$, while scores 5 and 6 suggest combined dementia and scores of 7 or more suggest multiinfarct dementia.

\section{Neuropathological methods}

Details of the neuropathological examination will be given in a separate communication (Paljärvi et al, in preparation). At necropsy, the right half of the brain was fixed for several weeks in $10 \%$ buffered formalin and was then subjected to a neuropathological examination. From the left half, samples were taken for biochemical analyses, and the remains were examined for gross pathology. No attempt was made to quantify the volume of ischaemic lesions either in this or the other hemisphere. Samples for paraffin embedding were taken from fifteen standard brain areas. The $8 \mu \mathrm{m}$ sections were stained with haematoxylin-eosin, Bielschowsky's silver method, and Congo red.

The silver stained sections were used to detect neuritic plaques, Alzheimer's neurofibrillary tangles, and neurons with granulovacuolar degeneration. A quantitative method was used to score the amount of plaques and tangles from 0 (none) to 10 (more than 40 structures per field of $1 \cdot 17$ $\mathbf{m m}^{2}$ ). The summary scores calculated included the Neocortical Tangle Score, obtained by summing up the scores of the medial frontal, angular, and medial temporal gyri. The gross and microscopic examinations were performed without knowledge of the clinical diagnosis.

Criteria for the neuropathological classification of dementia The case was considered as AD, if there were senile plaques and neurofibrillary tangles in the neocortex.' $A$ Neocortical Tangle Score of $\geqslant 2$ was required: this corresponds to at least three tangles in any neocortical field or solitary tangles in more than one sample. Numerical plaque density was not used as a separate criterion; moderate or high numbers of plaques, however, invariably accompanied tangles in the cortex. A diagnosis of multi-infarct dementia was made if there were any ischaemic lesions either macroscopically or microscopically and no neocortical tangles (score $<2$ ) were found. A diagnosis of combined dementia was made, if the criterion of $A D$ was fulfilled and there were ischaemic lesions in addition.

STATISTICAL METHODS

The Ischaemic Score distributions in the diagnostic groups were compared with the nonparametric KolmogorovSmirnov test. ${ }^{15}$ The $\chi^{2}$-test was used to identify items of the Score with a significantly different occurrence in the patient groups. The Score items were also subjected to discriminant function analyses using multiple linear and logistic models. The P7M (stepwise discriminant analysis) and PLR (stepwise logistic regression) programs of the BMDP software package were used. ${ }^{16}$ When regression functions are used to classify cases in the material which itself was used to derive the constants and coefficients, the rate of correct classification tends to be overestimated. Since no new independent validation material was available, the jackknife and cross validation procedures were used to get more realistic estimates. The jackknife method is a feature of the P7M program: each case is classified by regression functions computed from all the data except the case being classified. In the case of logistic regression, the material was randomly split half, and the functions obtained in one half were used to classify cases of the other.

\section{Results}

According to the neuropathological examination, AD, multi-infarct dementia and combined dementia accounted for $78 \%$ of the material (table 1). Two cases showed histological features of Parkinson's disease, and one case was thought to be due to normal pressure hydrocephalus. The neuropathological picture was considered nondiagnostic in 10 cases $(18.2 \%)$. Two of these showed hippocampal $\stackrel{\odot}{\complement}$ sclerosis as the sole abnormality. Three had a history? of schizophrenia and one of alcoholism. One further case displayed a rather high density of senile plaques in the neocortex (up to 15-20 per field), but no neocortical tangles were seen. In this case, therefore, the Alzheimer process may have been contributing to dementia but the picture was not diagnostic. Three cases $(5 \%)$ remained which had neither morphological abnormalities nor clinical clues for the cause of their dementia.

The correlations of clinical and neuropathological diagnosis are shown in table 2 . Sensitivity (true positive rate) in the case of $\mathrm{AD}$, for example, denotes the number of patients having both clinical and

Table 1 Neuropathological classification of 58 cases of dementia

\begin{tabular}{llc}
\hline Diagnostic category & $\begin{array}{l}\text { Number of } \\
\text { patients }\end{array}$ & $\begin{array}{l}\text { Percentage } \\
\text { of total }\end{array}$ \\
\hline Alzheimer's disease & 28 & $48 \cdot 3$ \\
Dementia with vascular pathology & 17 & $29 \cdot 3$ \\
Multi-infarct dementia & 11 & $19 \cdot 0$ \\
Combined dementia & 6 & 10.3 \\
Other causes & 13 & $22 \cdot 4$ \\
Parkinson's disease & 2 & $3 \cdot 4$ \\
Normal pressure hydrocephalus & 1 & $1 \cdot 7$ \\
No diagnostic pathology & $10^{*}$ & $18 \cdot 2$ \\
Total & 58 & $100 \cdot 0$ \\
\hline
\end{tabular}

*Hippocampal sclerosis only, 2; history of psychosis, 3; history of alcoholism, 1 
neuropathological diagnosis of $\mathrm{AD}$ divided by the total number of neuropathologically diagnosed $\mathrm{AD}$ cases. Specificity (true negative rate) for the clinical diagnosis of $\mathrm{AD}$ denotes the number of patients whose clinical and neuropathological diagnosis is other than AD divided by the total number of cases with a neuropathological diagnosis other than AD.

$\mathrm{AD}$ and multi-infarct dementia were moderately well diagnosed by the clinician (sensitivities and specificities over $70 \%$ ), whereas only one out of six combined cases was correctly identified. The group "other" as diagnosed by the clinician showed neither AD nor vascular type of pathology, and in this sense the specificity of this clinical diagnosis was $100 \%$. Altogether $35 / 58$ patients $(60.3 \%)$ were correctly placed into the four diagnostic categories. The most notable trend is perhaps the overdiagnosis of multi-infarct dementia: only in eight out of 19 patients was this clinical diagnosis confirmed, although two further patients turned out to suffer from a combination of pathologies including ischaemic softenings.

The occurrence of features of Hachinski's Ischaemic Score in the AD and multi-infarct dementia groups is shown in table 3 . The items suggesting vascular dementia were consistently more often found in the multi-infarct dementia group than in the AD group, but only six items were significantly more common in the former: stepwise deterioration, fluctuating course, relative preservation of personality, emotional incontinence, history of strokes, and focal neurological symptoms.

The mean Ischaemic Score was 2.9 in the $\mathrm{AD}$ group and 8.2 in the multi-infarct dementia group, while an intermediate figure of 4.5 was found in the combined group (fig). The AD and multi-infarct dementia groups differed significantly from each other $(p<0.001)$, whereas the small combined group differed significantly from neither.

Hachinski's Score was $64.4 \%$ successful (29/45) in classifying patients into three groups $(A D$, multiinfarct dementia, combined). Discriminant analysis using a linear model was only marginally better, pre- dicting one more case correctly. The same result was obtained with the "jackknife" classification (see the Methods section). Only two items of the Score were included in the discriminant functions: fluctuating course and focal neurological symptoms (table 4).

The multi-infarct dementia and combined groups were not properly distinguishable from each other on the basis of the Ischaemic Score. A more satisfactory result was obtained when the multi-infarct dementia and combined cases were lumped together: Hachinski's Score was then $73.3 \%$ successful (33/45) in making the discrimination between $A D$ and vascular dementias. If, instead of the original 4 , the score of 3 was used as the highest acceptable for $\mathrm{AD}, 35 / 45(\mathbf{7 7 . 8 \% )}$ were correctly classified (fig). A still better result was obtained with a logistic regression function, which identified correctly $37 / 45$ cases, or $82.2 \%$ (table 5 ). The model included fluctuating course, nocturnal confusion and focal neurological symptoms as the best discriminating Score variables. When the patients were randomly assigned into two groups and classified by the regression functions obtained from one half only, classification rate remained at $82-83 \%$ in the training sets and $78-82 \%$ in the validation sets (that is at most one additional case was misclassified).

\section{Discussion}

It is generally accepted that $\mathrm{AD}$ is the most common cause of dementia in old age, accounting for about half of the cases. The next most common individual condition is multi-infarct dementia (12-20\%), while the combination of these processes is found in a further $16-20 \%$. Some $10-20 \%$ remain for other known or unknown causes. ${ }^{17}$ Roughly similar proportions were found in the present study.

We have demonstrated that $A D$ and vascular dementias can be recognised clinically with moderate accuracy. Our results are more encouraging than those of Todorov et al. ${ }^{4}$ (see the introduction), a fact apparently attributable to the prospective design of our study. In the study by Müller and Schwartz, 37

Table 2 Correlation of clinical and neuropathological diagne ses of dementia in 58 patients. $29 / 45$ (64.4\%) of cases with $A D$, multi-infarct dementia or combined pathology are correctly classified by the original Hachinski's Ischaemic score 7 (see the Methods for criteria). AD, Alzheimer's disease; MID, multi-infarct dementia

\begin{tabular}{|c|c|c|c|c|c|c|c|}
\hline \multirow{2}{*}{$\begin{array}{l}\text { Clinical } \\
\text { diagnosis }\end{array}$} & \multicolumn{5}{|c|}{ Neuropathological diagnosis } & \multirow{2}{*}{$\begin{array}{l}\text { Sensitivity } \\
\text { (of clinical diagnosis, \%) }\end{array}$} & \multirow[t]{2}{*}{ Specificity } \\
\hline & $A D$ & $M I D$ & Combined & Other & Total & & \\
\hline $\begin{array}{l}\text { AD } \\
\text { MID } \\
\text { Combined } \\
\text { Other } \\
\text { Total }\end{array}$ & $\begin{array}{r}20 \\
6 \\
2 \\
0 \\
28\end{array}$ & $\begin{array}{r}1 \\
8 \\
2 \\
0 \\
11\end{array}$ & $\begin{array}{l}3 \\
2 \\
1 \\
0 \\
6\end{array}$ & $\begin{array}{r}4 \\
3 \\
0 \\
6 \\
13\end{array}$ & $\begin{array}{r}28 \\
19 \\
5 \\
6 \\
58\end{array}$ & $\begin{array}{l}71 \cdot 4 \\
72 \cdot 7 \\
16 \cdot 7 \\
46 \cdot 2\end{array}$ & $\begin{array}{r}73 \cdot 3 \\
76 \cdot 6 \\
92 \cdot 3 \\
100 \cdot 0\end{array}$ \\
\hline
\end{tabular}


Table 3 Presence of features of the Ischaemic Score in Alzheimer's disease $(A D ; n=28)$ and multi-infarct dementia $(M I D ; n=11)$

\begin{tabular}{|c|c|c|c|c|}
\hline \multirow[t]{2}{*}{ Feature } & \multirow[t]{2}{*}{ Weight } & \multicolumn{2}{|c|}{ Patients with feature\% } & \multirow{2}{*}{$\begin{array}{l}\text { Significance } \\
\left(\chi^{2}-t e s t\right)\end{array}$} \\
\hline & & $A D$ & $M I D$ & \\
\hline $\begin{array}{l}\text { Abrupt onset } \\
\text { Stepwise deterioration } \\
\text { Fluctuating course } \\
\text { Nocturnal confusion } \\
\text { Relative preservation of personality } \\
\text { Depression } \\
\text { Somatic complaints } \\
\text { Emotional incontinence } \\
\text { History of hypertension } \\
\text { History of strokes } \\
\text { Evidence of associated atherosclerosis } \\
\text { Focal neurological symptoms } \\
\text { Focal neurological signs }\end{array}$ & $\begin{array}{l}2 \\
1 \\
2 \\
1 \\
1 \\
1 \\
1 \\
1 \\
1 \\
2 \\
1 \\
2 \\
2\end{array}$ & $\begin{array}{r}21 \cdot 4 \\
10.7 \\
17 \cdot 9 \\
17 \cdot 9 \\
0 \cdot 0 \\
7 \cdot 1 \\
21 \cdot 4 \\
3 \cdot 6 \\
14 \cdot 3 \\
14 \cdot 3 \\
39 \cdot 3 \\
7 \cdot 1 \\
28 \cdot 6\end{array}$ & $\begin{array}{l}45 \cdot 5 \\
54 \cdot 5 \\
63 \cdot 6 \\
36 \cdot 4 \\
27 \cdot 3 \\
27 \cdot 3 \\
27 \cdot 3 \\
27 \cdot 3 \\
27 \cdot 3 \\
54 \cdot 5 \\
63 \cdot 6 \\
54 \cdot 5 \\
45 \cdot 5\end{array}$ & $\begin{array}{l}\text { NS } \\
p<0.01 \\
p<0.01 \\
N S \\
p<0.01 \\
N S \\
N S \\
p<0.05 \\
N S \\
p<0.01 \\
N S \\
p<0.001 \\
N S\end{array}$ \\
\hline
\end{tabular}

NS $=$ not significant.

Table 4 Classification of $A D, M I D$ and combined dementia cases by linear discriminant functions $\left(F=a_{0}+a_{1} x_{1}+a_{2} x_{2}+\ldots+a_{n} x_{n}\right)$ based on two clinical features. A case is classified into the group whose equation yields the highest function value

\begin{tabular}{|c|c|c|c|c|c|c|}
\hline $\begin{array}{l}\text { Diagnostic } \\
\text { group }\end{array}$ & $n$ & $\begin{array}{l}\text { nstant } \\
a_{0}\end{array}$ & $\begin{array}{l}\text { Variable } x_{1}= \\
\text { Fluctuating course } \\
\text { Coefficient } a_{1}\end{array}$ & $\begin{array}{l}\text { Variable } x_{2}=\text { Focal } \\
\text { Neurological symptoms } \\
\text { Coefficient } a_{2}\end{array}$ & & \\
\hline $\begin{array}{l}\text { AD } \\
\text { MID } \\
\text { Combined } \\
\text { Total }\end{array}$ & $\begin{array}{r}28 \\
11 \\
6 \\
45\end{array}$ & $\begin{array}{l}-1 \cdot 259 \\
-4 \cdot 773 \\
-2 \cdot 249\end{array}$ & $\begin{array}{l}1 \cdot 315 \\
5 \cdot 568 \\
3 \cdot 580\end{array}$ & $\begin{array}{l}1 \cdot 203 \\
6 \cdot 978 \\
3 \cdot 060\end{array}$ & $\begin{array}{r}21 \\
6 \\
3 \\
30\end{array}$ & $\begin{array}{l}75 \cdot 0 \\
54 \cdot 5 \\
50 \cdot 0 \\
66 \cdot 7\end{array}$ \\
\hline
\end{tabular}

of their 100 psychogeriatric patients had a psychiatric diagnosis of senile dementia (corresponding to SDAT), and in 32 cases $(86 \%)$ the final clinical-pathological diagnosis was the same. Of 24 patients with a clinical diagnosis of "psychosis associated with cerebral arteriosclerosis", only 12 $(50 \%)$ had this diagnosis confirmed at necropsy. As

Table 5 Classification of $28 A D$ cases and 17 vascular dementia cases (11 MID cases + 6 combined dementia cases) into two diagnostic categories by a logistic regression function $\left(F\right.$, below) based on three clinical features: $x_{1}=$ fuctuating course, $x_{2}=$ nocturnal confusion, $x_{3}=$ focal neurological symptoms. The function yields the probability of $A D$ when absent features are coded as -1 and features present as +1 . A cutpoint between 0.292 and 0.542 gives the results shown

\begin{tabular}{|c|c|c|c|c|}
\hline \multirow{2}{*}{$\begin{array}{l}\text { Diagnostic } \\
\text { category }\end{array}$} & \multicolumn{2}{|c|}{ Predicted as } & \multirow[t]{2}{*}{ Total } & \multirow[t]{2}{*}{ Percent correct } \\
\hline & $S D A T$ & Vascular & & \\
\hline $\begin{array}{l}\text { AD } \\
\text { Vascular } \\
\text { Total }\end{array}$ & $\begin{array}{r}25 \\
5 \\
30\end{array}$ & $\begin{array}{r}3 \\
12 \\
15\end{array}$ & $\begin{array}{l}28 \\
17 \\
45\end{array}$ & $\begin{array}{l}89 \cdot 3 \\
70 \cdot 6 \\
82 \cdot 2\end{array}$ \\
\hline \multicolumn{5}{|c|}{$\exp \left(-1.217-1.382 x_{1}-0.857 x_{2}-1.958 x_{3}\right)$} \\
\hline
\end{tabular}

the exact diagnostic criteria are not given in the report, comparison to the present results is difficult. The prospective study by Sulkava $\mathrm{et}^{\mathrm{a}} \mathrm{l}^{6}$ was confinedo to cases with a clinical diagnosis of primary? degenerative dementia. At necropsy, 22/27 patients $(81 \%)$ turned out to suffer from AD. None of the remaining patients were reported as showing ischaemic lesions. The authors did not use Hachinski's Score in their clinical classification: their study shows that a high accuracy for the diagnosis of $A D$ may be reached by basing the diagnosis on positive criteria for primary degenerative dementia.

In the present study, the neuropathological diagnosis was used as the point of reference in evaluating the success of the clinical diagnosis. This should not be taken to mean that the neuropathological diagnosis was always the correct one, since sources of error and inconsistency did exist in our study design. Many of these have to do with the role of ischaemia as an aetiological factor. First, some patients may have undergone a stroke after the initial thorough clinical evaluation suggesting AD. Second, some of the small cerebral softenings may have been overlooked in the postmortem examination, particularly those in the left hemisphere not available for the pathologist. Third, presence of even the smallest 


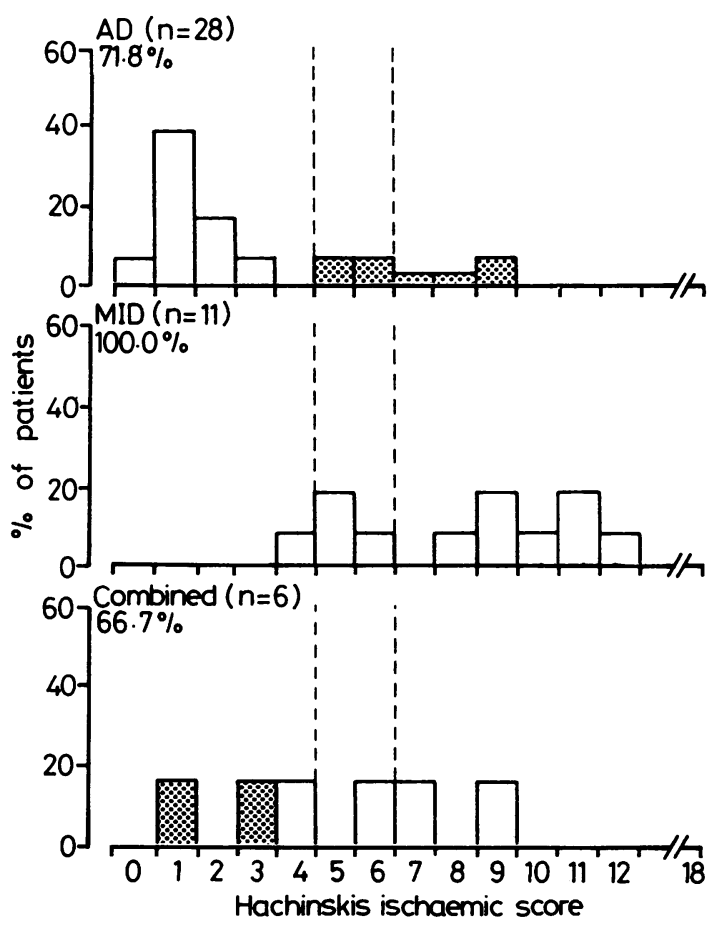

Fig Percentage distributions of Ishaemic Scores in three neuropathologically diagnosed groups of dementia. The broken lines show the original cutpoints ( $A D$ 0-4, multi-infarct dementia $\geqslant 7$ ). The percentages (and open bars) denote patients classified correctly using an alternative cutpoint and a dichotomous classification: $A D 0-3$, vascular dementia (multi-infarct dementia or combined) $\geqslant 4$. Hatched bars show incorrectly diagnosed patients. $n=$ number of patients.

ischaemic softenings led to the diagnosis of multiinfarct dementia or combined dementia even though their significance for the mental deterioration may have been negligible. Quantitation of the ischaemic lesions (for example such as that used by Tomlinson et al. ${ }^{1}$ ) might be helpful in this respect. It is difficult to say what is the net effect of these error sources in the present study.

The present results attest the usefulness of Hachinski's Ischaemic Score ${ }^{7}$ in differentating between the major forms of senile dementia. This score is based on the diagnostic criteria of multiinfarct dementia as presented in a textbook of psychiatry. ${ }^{18}$ The score includes thirteen items, five of which are given a point value of 2 , as they are considered more important than the others. The weights are not based on formal statistical grounds. In the original material ${ }^{7}$ the scores made it possible to classify the patients into two groups without any overlap. The group of fourteen patients with primary degenerative dementia scored 4 or below, whereas the ten patients with multi-infarct dementia scored 7 or higher. The problem with that study is that the aetiological diagnosis of dementia was made on clinical grounds, that is without neuropathological confirmation. The same criticism holds to some extent for the study by Loeb and Gandolfo, ${ }^{19}$ who assessed the validity of the Ischaemic Score on the basis of CT scan. Only $69 \%$ of the patients with SDAT scored 4 or lower, while $95 \%$ of the multiinfarct dementia cases had scores equal or higher than 7; some overlap, therefore, was found in this material.

To our knowledge, so far the only attempt to validate neuropathologically the Ischaemic Score is the retrospective investigation by Rosen et al. ${ }^{20}$ All of their five SDAT patients had Ischaemic Scores of 5 or less, whereas the scores of the four multi-infarct dementia and five mixed (combined) cases ranged from 7 to 14. Thus, no overlap between SDAT and vascular cases was found. This particular result did not stand the test of our own prospective study. Rosen and coworkers found (as did we) that the Ischaemic Score cannot properly separate the combined cases from the multi-infarct dementia group. It must be admitted that our combined group of six patients is too small to justify strong conclusions. On the other hand, we feel that it is impossible even in principle to completely separate these groups by means of vascular symptomatology alone, because there is no reason why some of the combined cases could not have as many vascular signs and symptoms as any multi-infarct dementia case. To make a more successful distinction, one clearly also needs positive indicators for the Alzheimer process in the combined patients.

We explored the possibilities of improving the performance of the Ischaemic Score by assigning new weights for the score items. The items that in the present study had significantly different distributions in the $A D$ and multi-infarct dementia groups are not identical to those given the higher point value of 2 in the original Score (table 3). The logistic regression function used to discriminate between $\mathrm{AD}$ and vascular dementias stressed the diagnostic importance of fluctuating course, nocturnal confusion, and focal neurological symptoms. The earlier validation studies ${ }^{19}{ }^{20}$ stress some other items, and indeed one does not expect far-reaching unity in this respect, since item identification must vary from one diagnostician to another. However, all of these studies (including our own) agree that neither depression nor evidence of associated atherosclerosis are particularly helpful in diagnosis.

Although the ultimate diagnosis of $\mathrm{AD}$, multi- 
infarct dementia and combined dementia is a neuropathological one, we conclude that a careful analysis of history, symptoms, and signs may result in a serviceable clinical diagnosis at the bedside. This diagnosis, particularly if supported by neurophysiological and CT findings, should be reasonably useful in studies on epidemiology, genetics, and therapy of dementia.

Financial support was obtained from the Sigrid Jusélius Foundation.

\section{References}

'Tomlinson BE, Blessed G, Roth M. Observations on the brains of demented old people. J Neurol Sci 1970;11:205-42.

${ }^{2}$ Hachinski VC, Lassen NA, Marshall J. Multi-infarct dementia - a cause of mental deterioration in the elderly. Lancet $1974 ; 2: 207-9$.

${ }^{3}$ Liston EH, La Rue A. Clinical differentiation of primary degenerative and multi-infarct dementia: A critical review of the evidence. Biol Psych 1983;18:1451-65.

${ }^{4}$ Todorov AB, Go RCP, Constantidinis J, Elston RC. Specificity of the clinical diagnosis of dementia. $J$ Neurol Sci 1975;26:81-98.

${ }^{5}$ Müller HF, Schwartz G. Electroencephalograms and autopsy findings in geropsychiatry. $J$ Gerontol 1978;33:504-13.

- Sulkava R, Haltia M, Paetau A, Wikström J, Palo J. Accuracy of clinical diagnosis in primary degenerative dementia: correlation with neuropathological findings. J Neurol Neurosurg Psychiatry 1983;46:9-13.

${ }^{7}$ Hachinski VC, Iliff LD, Zhilka E, Du Boulay GHD, McAllister VL, Marshall J, Russell RWR, Symon L. Cerebral blood flow in dementia. Arch Neurol
1975;32:632-7.

${ }^{8}$ Mölsä PK, Marttila RJ, Rinne UK. Epidemiology of dementia in a Finnish population. Acta Neurol Scand 1982;65:541-52.

${ }^{9}$ Mölsä P. Dementia. A clinical study in the Finnish population. Research Reports from the Department of Neurology, University of Turku, No 17, Turku 1980.

${ }^{10}$ Isaacs B, Walkey FA. The assessment of the mental state of elderly hospital patients using a simple questionnaire. Am J Psychiatry 1963;120:173-4.

" Isaacs B, Walkey FA. A simplified performance test for elderly hospital patients. J Am Geriatr Soc 1963;11:1089-94.

12 Isaacs B, Walkey FA. Measurement of mental impairment in geriatric practice. Geront Clin 1964;6:11423.

${ }^{13}$ Luria AR. The Working Brain. An Introduction to Neuropsychology. London: Penguin Press 1973.

${ }^{14}$ Portera-Sanchez A, del Ser T, Bermejo F, Arredondo JM. Clinical diagnosis of senile dementia of Alzheimer type and vascular dementia. In: Terry RD, Bolis CL, Toffano G, eds. Neural Aging and its Implications in Human Neurological Pathology (Aging, Vol. 18). New York: Raven Press, 1982:169-88.

15 Siegel SS. Nonparametric Statistics for the Behavioral Sciences. New York: McGraw-Hill 1956.

${ }^{16}$ Dixon WJ, ed. BMDP Statistical Software. Berkeley, Los Angeles, London: University of California Press, 1983.

${ }^{17}$ Wells C. Role of stroke in dementia. Stroke 1978;9:1-3.

${ }^{18}$ Mayer-Gross W, Slater E, Roth M. Clinical Psychiatry, 3rd ed. London: Bailliere, Tindall \& Carssell, 1969.

${ }^{19}$ Loeb C, Gandolfo C. Diagnostic evaluation of degenerative and vascular dementia. Stroke 1980;14:399-401.

${ }^{20}$ Rosen WG, Terry RD, Fuld PA, Katzman R, Peck A. Pathological verification of Ischemic Score in differentiation of dementias. Ann Neurol 1980; 7:486-8. 